\title{
The Effect of Thermotropic LC Polyesters on the Crystallization Rate and Mechanical Properties of Poly(ethylene terephthalate) Film
}

\author{
Yun Su KIM and In Jae CHUNG ${ }^{\dagger}$ \\ Department of Chemical Engineering, Korea Advanced Institute of Science and Technology, \\ P.O. Box 150 Cheongryang, Seoul, Korea 130-650
}

(Received February 25, 1991)

\begin{abstract}
The thermotropic liquid crystalline polyesters (TLCPs) with two kind of methylene groups in a main chain were synthesized by melt polycondensation. One molecule has repeating units in the following composition;

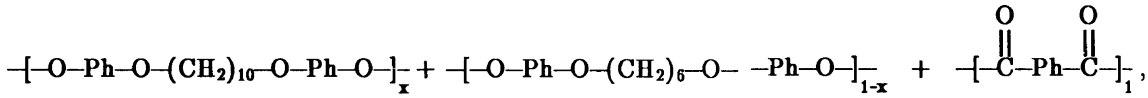

where Ph means $p$-phenylene unit and $x$ was controlled to have values of $1,0.7,0.5,0.3$, and 0 . The random copolyesters $(x=0.7,0.5$, and 0.3$)$ revealed lower melting temperatures and wider nematic ranges between melting and isotropic transition temperatures than the two homopolyesters ( $x=1$ and 0 ). The blends of poly(ethylene terephthalate) and TLCPs with $x=1,0.7$, and 0.3 were prepared by twin screw extrusion. A sheet of the blend was prepared by single screw extrusion and sheet casting, and a film was made by stretching biaxially and annealing the sheet. The effect of TLCP on crystallization rate was dominant in the sheet while TLCP addition itself did not contribute much to the crystallization when compared with the stress induced crystallization in the cold stretching of a stretched and quenched film. The strength and modulus were improved in transverse direction (TD) as well as in machine direction (MD) by adding TLCP. In particular the blend film with random copolyester having $x=0.3$ showed high improvements in strength and modulus. The dimensional stability of the film was also improved by the addition of the TLCPs.

KEY WORDS Thermotropic Liquid Crystalline Polyesters / Poly(ethylene terephthalate) / Blend Film / Biaxial Stretching / Heat Treatment / Crystallization Rate / Young's Modulus / Dimensional Stability /
\end{abstract}

A lot of research groups around polymer science and technology have been interested in the utilization of thermotropic liquid crystalline polyesters (TLCPs) during the last decade. Clearly it is known that most of TLCPs have a low melt viscosity because of molecular orientation by elongational and/or shearing forces during processing, and have good mechanical properties because they have a long relaxation time and maintain the orientated state. Some of TLCPs have been commercialized, and a number of papers have presented properties of their blends with isotropic polymers. ${ }^{1-4}$ The blends have improved mechanical properties by forming microfibril structure of TLCP in the flow direction by the process of fiber spinning and injection molding of the blend. It is said that the mechanical properties of blends with TLPCs are significantly affected by the mode of dispersion, the shape and the orientation of TLCP, and the interfacial adhesion between two polymers. ${ }^{5-8}$ Shin and Chung studied that the TLCP with long flexible spacers in a main chain showed nematic mesophase in the melt and its blend with poly(ethylene terephthalate) (PET) had

\footnotetext{
† To whom all correspondence should be addressed.
} 
highly improved tensile strength and modulus due to the good interfacial adhesion and microfibril structure of TLCP in the fiber. ${ }^{9}$ The present paper concerns the properties of the extruded, stretched biaxially, and/or heattreated films of the PET blend with TLCPs having two kind of methylene groups in a main chain.

\section{EXPERIMENTAL}

\section{TLPC Synthesis and Film Preparation}

TLCPs based on 4,4'-dihydroxydiphenoxyalkane were synthesized by melt polycondensation in a high temperature and high vacuum vessel equipped with stirrer to obtain high molecular weight polymers. The polymerization method was described in a previous paper. ${ }^{10}$ The reaction scheme is as follows:

$$
\left.-\left(\mathrm{CH}_{2}\right)_{6}^{-O}-\mathrm{O}-\mathrm{OH}\right\}+\mathrm{n}\{\mathrm{Cl}-\mathrm{C}-\mathrm{O}-\mathrm{C}-\mathrm{Cl}\} \stackrel{-(2 \mathrm{n}-1) \mathrm{HCl}}{\longrightarrow}
$$

To make homopolyesters $x$ was controlled to 1 and 0 , and to make random copolyesters $x$ was controlled to $0.7,0.5$, and 0.3 . The matrix polymer PET was manufactured by SKC Limited in Korea and had the intrinsic viscosity of 0.62 in $o$-chlorophenol solution at $20^{\circ} \mathrm{C}$. The TLCPs with $x=1,0.7$, and 0.3 , and PET were dried in a vacuum oven and introduced into a twin screw extruder (Plasti-Corder PLE331) at $290^{\circ} \mathrm{C}$ and $50 \mathrm{rpm}$ to make blends. The blends were extruded by Haake extruder (Model 23-18-000) at $290^{\circ} \mathrm{C}$ and $90 \mathrm{rpm}$ to be a sheet, and the draw ratio was fixed at 2.0. The sheets were quenched by a chill roll at $25^{\circ} \mathrm{C}$ and then stretched biaxially in hot air of $100^{\circ} \mathrm{C}$ at the rate of $10 \mathrm{~mm} \mathrm{~s}^{-1}$ (initial size $=100 \mathrm{~mm} \times 100$ $\mathrm{mm})$. The thickness of the films drawn at the draw ratio of $3.5 \times 3.5$ in the machine direction
(MD) and transverse direction (TD) was about $30 \mu \mathrm{m}$. The films were treated thermally under a load in a silicone oil bath.

\section{Measurements}

The transition temperatures of the TLCPs and the crystallization rate constants of the sheet and film were analyzed from the dynamic heating curve of DSC (du Pont 910 Thermal analyzer). It was observed that the crystallization of oriented PET does not follow the Avrami theory. ${ }^{11}$ The rate constant $k(T)$ of oriented PET can be calculated from dynamic heating procedure using the following equation $^{12}$ :

$$
\frac{1}{A}\left(\frac{\partial H}{\partial \mathrm{t}}\right)_{T}=k(T)\left(1-\frac{Y}{A}\right)
$$

where $A$ is the total area of the thermogram peak, $Y$ the area under the thermogram peak up to a temperature, and $(\partial H / \partial t)_{T}$ the height at this temperature. The tensile modulus and strength were measured by Instron tensile tester (Model 4201) operated at a crosshead speed of $10 \mathrm{~mm} \mathrm{~min}^{-1}$ on $25 \times 5 \mathrm{~mm}$ specimens. For the investigation of morphology the fracture surfaces were examined by using SEM (Hitachi model 1510). Wide angle X-ray diffraction patterns were analyzed to see the effect of TLCP and heat treatment on oriented crystallization of the blend film. Also, heat shrinkage data obtained by free annealing at various temperatures were analyzed to see the effect of TLCPs on the dimensional stability of the PET film.

\section{RESULTS AND DISCUSSION}

\section{Characteristics of the TLCPS}

The inherent viscosity $\left(\eta_{\text {inh }}\right)$ and thermal properties of the TLCPs are shown on Table I. The previous papers ${ }^{13,14}$ reported the detailed thermal properties for the homopolyesters with methylene groups in a main chain. The thermal properties for the several copolyesters showed qualitatively similar be- 
Table I. Inherent viscosity and thermal properties of the LC polyesters ${ }^{a}$

\begin{tabular}{|c|c|c|c|c|}
\hline \multirow{2}{*}{$x$-Value } & $\eta_{\mathrm{inh}}^{*}$ & $T_{\mathrm{m}}$ & $T_{\mathrm{i}}$ & $T_{\mathrm{d}}$ \\
\hline & $\mathrm{dl} \mathrm{g}^{-1}$ & ${ }^{\circ} \mathrm{C}$ & ${ }^{\circ} \mathrm{C}$ & ${ }^{\circ} \mathrm{C}$ \\
\hline 1 & 0.98 & 277 & 338 & 450 \\
\hline 0.7 & 1.02 & 236 & 355 & 418 \\
\hline 0.5 & 0.88 & 222 & 343 & 415 \\
\hline 0.3 & 1.00 & 256 & 358 & 427 \\
\hline 0 & 0.85 & 299 & 374 & 435 \\
\hline
\end{tabular}

a Measured in $p$-chlorophenol solution at $0.2 \mathrm{gdl}^{-1}$ and $75^{\circ} \mathrm{C}$.

havior to the previous data. Chen and Lens ${ }^{14}$ reported that molecular weight of the polymer had an important effect on the transition temperature below about $\eta_{\text {inh }}=0.7$ and the transition temperature had a constant value above $\eta_{\text {inh }}=0.75$ in the thermotropic homopolyester with decamethylene group in a main chain. So in our experiment the TLCPs with decamethylene and/or hexamethylene groups in a main chain may have no dependence of molecular weight on transition temperatures because they have the values of $\eta_{\mathrm{inh}}=0.85$ 1.02. Figure 1 shows the melting $\left(T_{\mathrm{m}}\right)$ and isotropic $\left(T_{\mathrm{i}}\right)$ transition temperatures of homopolyesters and copolyesters. Polarized microscopy revealed that they have nematic mesophase between $T_{\mathrm{m}}$ and $T_{i}$. The random copolyesters ( $x=0.7,0.5$ and 0.3 ) have lower melting temperatures and wider nematic ranges than the two homopolyesters ( $x=1$ and 0$)$. And the lowest melting temperature is shown in the copolyester with $x=0.5$. From these results it is suggested that copolyesters may be more processible in a nematic liquid crystalline state. The thermal degradation temperatures are over $410^{\circ} \mathrm{C}$ (Table I).

\section{Crystallization of Oriented PET}

Table II shows initiation and peak temperatures of crystallization for the blend, the sheet and the film. The samples were all quenched after processing. In the blend and the sheet $T_{\mathrm{hi}}$ and $T_{\mathrm{hp}}$ are decreased as TLCP content

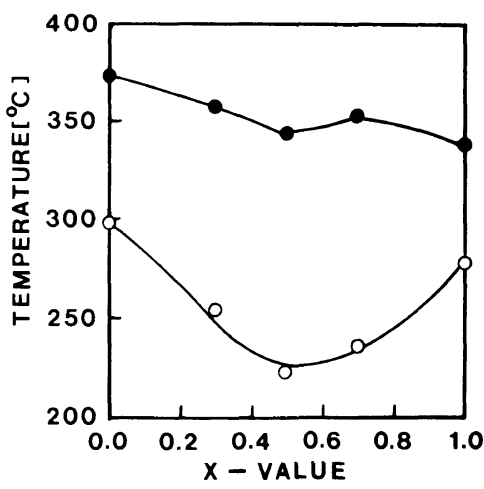

Figure 1. Melting $(\bigcirc)$ and isotropic (O) transition temperatures of thermotropic LC homopolyesters and copolyesters.

Table II. Initiation and peak temperatures of crystallization in heating $\left(T_{\mathrm{hi}}, T_{\mathrm{hp}}\right)$ mode for the PET-LCP $(x=0.3)$ blend, the sheet and the film. The scan rate was $10^{\circ} \mathrm{C} \mathrm{min}^{-1}$

\begin{tabular}{|c|c|c|c|}
\hline & LCP content & $T_{\mathrm{hi}}$ & $T_{\mathrm{hp}}$ \\
\hline & $w t \%$ & ${ }^{\circ} \mathrm{C}$ & ${ }^{\circ} \mathrm{C}$ \\
\hline \multirow{4}{*}{ Blend $^{a}$} & 0.0 & 112 & 122 \\
\hline & 1.5 & 110 & 119 \\
\hline & 3.0 & 107 & 116 \\
\hline & 5.0 & 104 & 114 \\
\hline \multirow{4}{*}{ Sheet $^{b}$} & 0.0 & 107 & 119 \\
\hline & 1.5 & 105 & 116 \\
\hline & 3.0 & 104 & 114 \\
\hline & 5.0 & 103 & 113 \\
\hline \multirow{4}{*}{ Film $^{\mathrm{c}}$} & 0.0 & 80 & 111 \\
\hline & 1.5 & 80 & 104 \\
\hline & 3.0 & 79 & 106 \\
\hline & 5.0 & 80 & 112 \\
\hline
\end{tabular}

a Blend quenched from melt at $290^{\circ} \mathrm{C}$.

b Sheet extruded at $290^{\circ} \mathrm{C}$ and $90 \mathrm{rpm}$ and quenched.

c Film stretched by draw ratio of $\mathrm{MD} \times \mathrm{TD}=3.5 \times 3.5$ at $100^{\circ} \mathrm{C}$ and quenched.

increases up to $5 \mathrm{wt} \%$, but the stretched and quenched films do not show this kind of tendency and have quite lower $T_{\mathrm{hi}} \mathrm{s}$ and $T_{\mathrm{hp}} \mathrm{s}$. To analyze the effect of TLCP content on crystallization rate of the PET sheet and film, the crystallization rate constant was calculated from dynamic heating curve of DSC (scan 


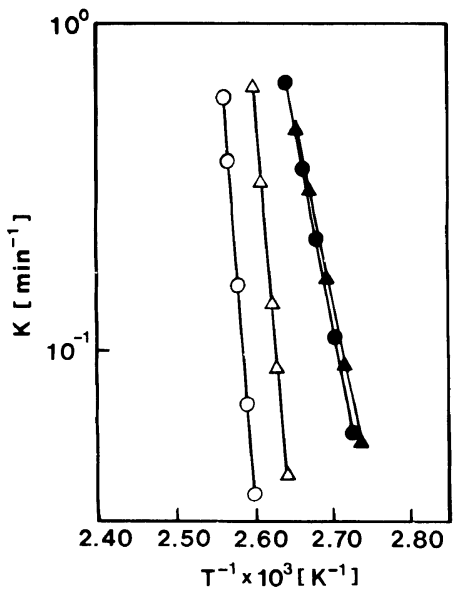

Figure 2. Crystallization rate constant as a function of the reciprocal of absolute temperature, $1 / T$, for extruded sheet (open symbols) and stretched film (closed symbol): pure PET $(\bigcirc)$ and the blend with $5 \mathrm{wt} \%$ of LCP having $x=0.3(\triangle)$.

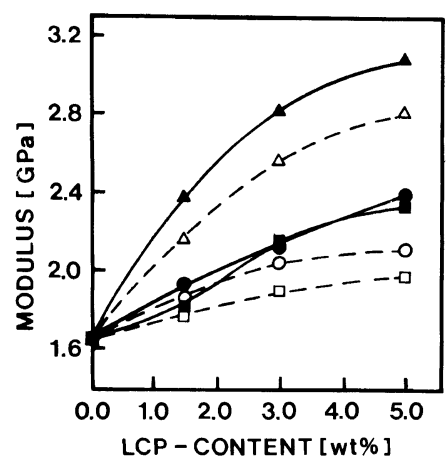

Figure 3. Young's modulus in MD (closed symbol) and TD (open symbol) of PET-LCP blend film stretched by draw ratio of $\mathrm{MD} \times \mathrm{TD}=3.5 \times 3.5$ at $100^{\circ} \mathrm{C}$, simultaneously: $x=1(\square), x=0.7(\bigcirc)$, and $x=0.3(\triangle)$.

rate $=5^{\circ} \mathrm{Cmin}^{-1}$ ) and was shown in Figure 2. The rate constants are higher for the stretched film than for the sheet. They are increased for the sheet by containing TLCP but they remain almost constant for the film as TLCP content increases. These results suggest that for the blend and quenched sheet the TLCP acts as a nucleating agent for the crystallization of PET, while for the stretched and quenched film the TLCP does not contribute much because of the stress induced crystallization of PET itself.

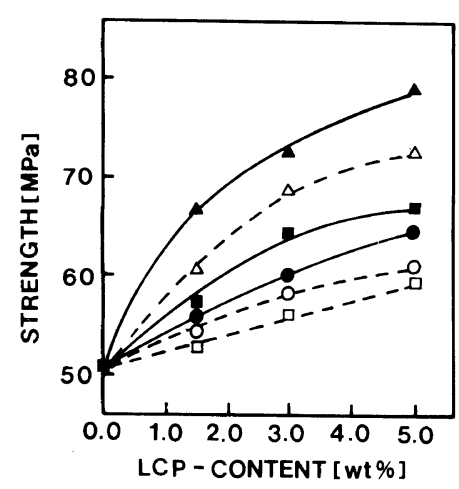

Figure 4. Tensile strength in MD (closed symbol) and TD (open symbol) of PET-LCP blend film stretched by draw ratio of $\mathrm{MD} \times \mathrm{TD}=3.5 \times 3.5$ at $100^{\circ} \mathrm{C}$, simultaneously: $x=1(\square), x=0.7(\bigcirc)$, and $x=0.3(\triangle)$.

\section{Mechanical Properties}

Figure 3 shows the Young's modulus of the blend film in MD and TD. Pure PET shows the same muduli in MD and TD, but the blend shows a slightly higher modulus in MD than in TD, and the moduli increase as TLCP content increases up to $5 \mathrm{wt} \%$. And the blend with copolyester having $x=0.3$ shows the highest modulus. Especially the modulus is improved about 2 times higher for the blend with $5 \mathrm{wt} \%$ of the TLCP than for the pure PET film. Figure 4 shows the tensile strength of the blend film. The previous papers ${ }^{1-3}$ reported a highly improved Young's modulus but a very poor tensile strength in the blend of TLCP and isotropic polymer. But in this blend the tensile strength was also highly improved due to the good interfacial adhesion. ${ }^{9}$

Figure 5 shows the Young's modulus of the blend films in MD which are first stretched and then annealed under the load of $30 \mathrm{MPa}$ in MD for $7 \mathrm{~min}$ at $160^{\circ} \mathrm{C}$. In this film stress induced crystallization is observed as shown in Figure 6. Totally the heat treatment improved the modulus. And the modulus continuously increases as TLCP content increases up to $5 \mathrm{wt} \%$ for the blend with copolyesters having $x=0.3$ and 0.7 , but it is almost constant for the blend with homopolyester having $x=1$.

Figure 6 shows wide angle X-ray diffraction 


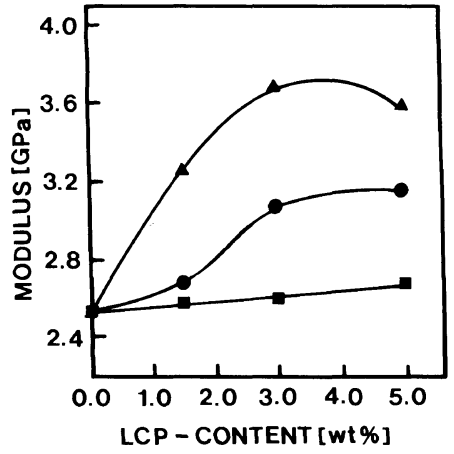

Figure 5. Young's modulus of PET-LCP blend films in MD that were first stretched by the draw ratio of $\mathrm{MD} \times \mathrm{TD}=3.5 \times 3.5$ at $100^{\circ} \mathrm{C}$ and then annealed under a load of $30 \mathrm{MPa}$ in $\mathrm{MD}$ for $7 \mathrm{~min}$ at $160^{\circ} \mathrm{C}: x=1$ (口), $x=0.7(\mathbf{O})$, and $x=0.3(\mathbf{A})$.

patterns of the blend films. The directions of the incident $\mathrm{X}$-rays are perpendicular to the film surface. The pattern unannealed shows amorphous state for the film blended with a low content of TLCP and stretched. But the pattern annealed under a load shows an oriented crystalline state. They (Figure 6(b) and (c)) have three sharp equatorial arcs at $d$-spacings of $5.14,3.87$, and $3.43 \AA$, and separated off-equatorial arcs appear at $d$ spacings of 5.40 and $4.07 \AA$ for the pure PET film (Figure 6(c)). These results suggest that a slightly more oriented crystalline pattern is shown for the pure PET film than for the blend film, the effective molecular orientation of the blend is decreased due to the presence of strongly bound TLCP particles.

The fracture surface of the film shows the spherical shape of TLCP domain for the blend with homopolyester, but a little crooked shape for the blend with copolyester having $x=0.3$ as shown in Figure 7. There is also some discrete fracture of the matrix around the TLCP particles and some fuzzy surfaces of the dispersed TLCP component. This implies a sign of good adhesion of the TLCP with the matrix polymer. PET and TLCP having $x=1$ were reported to have a good interfacial adhesion in the blend fiber while they were immiscible. ${ }^{9}$

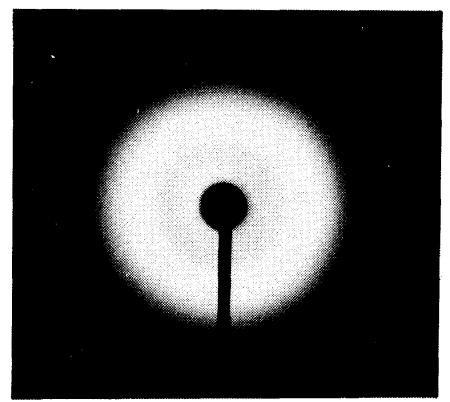

a
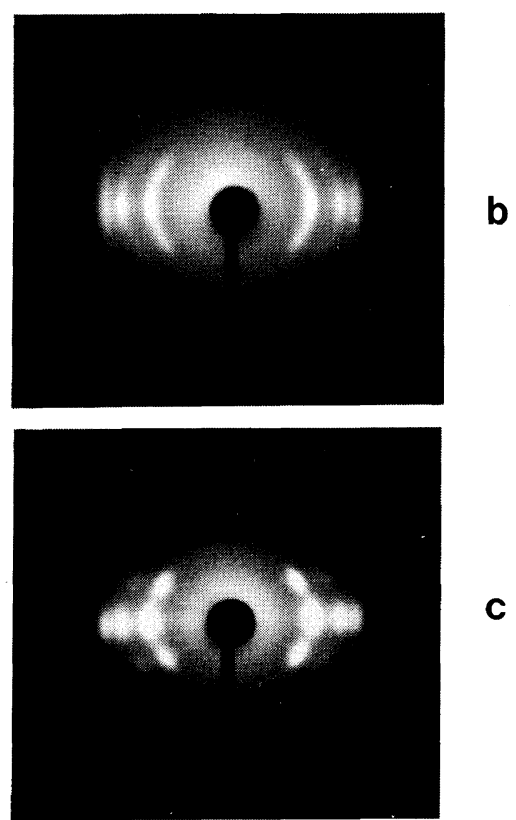

Figure 6. WAXD patterns of the PET-LCP $(x=0.3)$ blend films that were first stretched by the draw ratio of $\mathrm{MD} \times \mathrm{TD}=3.5 \times 3.5$ at $100^{\circ} \mathrm{C}$ and then annealed under a load of $30 \mathrm{MPa}$ in MD for $7 \mathrm{~min}$ at $160^{\circ} \mathrm{C}$ : (a) $5.0 \mathrm{wt} \%$ LCP and unannealed, (b) $5.0 \mathrm{wt} \% \mathrm{LCP}$ and annealed, and (c) pure PET and annealed.

Ko et al. ${ }^{4}$ reported that the Young's moduli in MD and TD increased with the TLCP content up to $40 \mathrm{wt} \%$ because of strong adhesion at the interface without fibril formation of TLCP (LCP2000 made by Celanese Corp.) in an extruded cast PET film. Their results are similar to our results after cold stretching in the low content of TLCP. They also observed Young's modulus in MD for the blends that were annealed at $160^{\circ} \mathrm{C}$ for $1 \mathrm{~h}$. The 


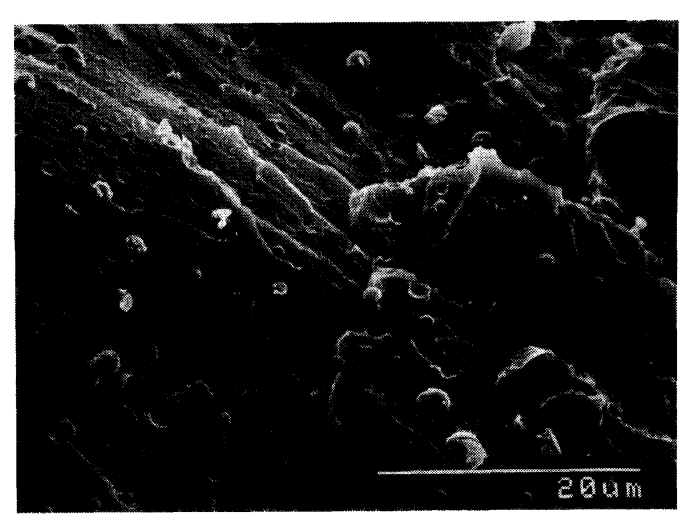

a

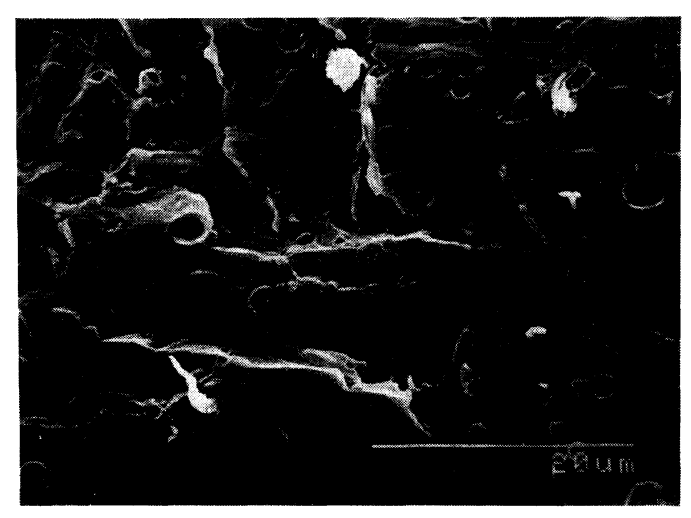

b

Figure 7. Fracture surface (which is perpendicular to MD) of PET sheet blended with LCP of $5 \mathrm{wt} \%$ having (a) $x=1$ and (b) $x=0.3$.

values became considerably higher by the annealing due to the promoted crystallization of PET and showed little dependence of TLCP composition. But in our experiment the tensile property of the blend with the copolyester $(x=0.3)$ is affected significantly not only by the PET crystallinity and orientation but also by the TLCP content as shown in Figure 5.

In certain uses of PET films the dimensional stability is very important as well as the tensile property. Heat shrinkage represents a sort of dimensional stability. Heat shrinkage in MD versus annealing temperature for the blend

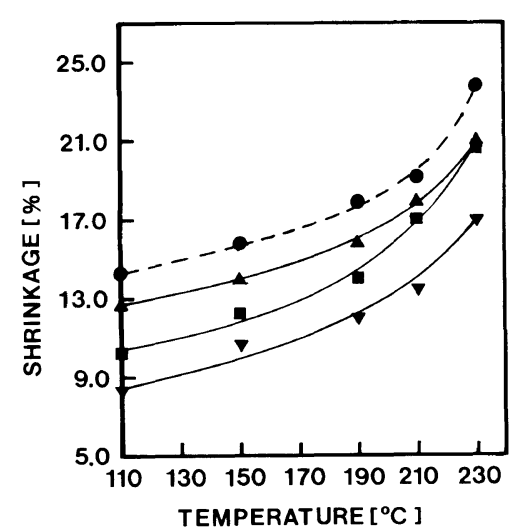

Figure 8. Heat shrinkage in MD vs. annealing temperature for pure PET and the blend films with LCP having $x=0.3$ that were first stretched by the draw ratio of $\mathrm{MD} \times \mathrm{TD}=3.5 \times 3.5$ at $100^{\circ} \mathrm{C}$ and then freely annealed for $20 \mathrm{~min}$; pure PET (O), LCP of $1.5 \mathrm{wt} \%(\boldsymbol{\Delta}), 3.0 \mathrm{wt} \%$ ( $\boldsymbol{\square})$, and $5.0 \mathrm{wt} \%(\nabla)$.

films becomes smaller by the addition of TLCP (Figure 8), that is, the dimensional stability of of the PET film is improved.

\section{CONCLUSION}

A copolyester may be more processible than a homopolyester in a nematic melt state because the former has a lower melting transition temperature and wider nematic range than the latter. A TLCP promotes the crystallization of PET as a nucleating agent, but in the oriented and quenched film the effect of TLCP on crystallization rate is almost negligible when compare with the stress induced crystallization of PET itself. The TLCPs act as a reinforcing agent of PET film for the improvement of tensile properties in the blends, especially in the blend with copolyester having $x=0.3$. Also the dimensional stability of the PET film is improved by the addition of the TLCPs.

Acknowledgment. We would like to thank SKC Limited for the financial support and the PET supply in this work. 


\section{Properties of LCP-PET Blend Films}

\section{REFERENCES}

1. P. Zhuang, T. Kyu, and J. L. White, Polym. Eng. Sci., 28, 1095 (1988).

2. A. I. Isayev and M. Modic, Polym. Composites, 8, 158 (1987).

3. F. P. LaMantia, A. Valenza, M. Paci, and P. L. Magagnini, J. Appl. Polym. Sci., 38, 583 (1989).

4. C. U. Ko, G. L. Wilkes, and C. P. Wong, J. Appl. Polym. Sci., 37, 3063 (1989).

5. T. Nishimura and H. Sakai, Kobunshi Ronbunshu, 45, 401 (1988).

6. A. Siegman, A. Dagan, and S. Kenig, Polymer, 26, 1325 (1985)
7. G. Kiss, Polym. Eng. Sci., 27, 410 (1987).

8. K. G. Blizard and D. G. Baird, Polym. Eng. Sci., 27, 653 (1987)

9. B. Y. Shin and I. J. Chung, Polym. Eng. Sci., 30, 13 (1990).

10. B. Y. Shin and I. J. Chung, Polym. J., 21, 851 (1989).

11. F. S. Smith and R. D. Steward, Polymer, 15, 283 (1974).

12. T. Sun, J. Pereira, and R. S. Porter, J. Polym. Sci., Polym. Phys. Ed., 22, 1163 (1984).

13. S. Antoun, R. W. Lenz, and J. I. Jin, J. Polym. Sci., Polym. Chem. Ed., 19, 1901 (1981).

14. G. Chen and R. W. Lenz, J. Polym. Sci., Polym. Chem. Ed., 22, 3189 (1984). 